\title{
Características Regionais da Evolução do Valor Bruto da Produção Agropecuária Municipal no Rio Grande do Sul entre 1970 e 2006
}

\section{Regional Characteristics of the Evolution of the Municipal Gross Value of Production of Agricultural and Livestock in Rio Grande do Sul between 1970 and 2006}

\author{
Dilson Trennepohl* \\ Lucir Reinaldo Alves** \\ Antônio Joreci Flores***
}

Resumo: Neste artigo estão apresentados os resultados da análise realizada sobre a evolução do Valor Bruto da Produção Agropecuária (VBPA) municipal no Rio Grande do Sul durante o período de 1970 até 2006. Os dados do VBPA de 1970 foram obtidos diretamente do Censo Agropecuário de 1970 e atualizados monetariamente pelo Índice Geral de Preços - Disponibilidade Interna (IGP-DI) para valores em reais de 2006. Os dados referentes ao VBPA de 2006, obtidos do Censo Agropecuário de 2006, através do Sistema IBGE de Recuperação Automática (Sidra), foram convertidos para a mesma base territorial dos municípios de 1970, através do sistema de conversão (PAIVA, 2007), utilizando o critério de área municipal. Com tais procedimentos, os dados tornaram-se comensuráveis, expressos na mesma unidade monetária e referenciados às unidades municipais com a mesma área territorial. Foram feitas análises do desempenho de todos os municípios e das dez principais atividades agropecuárias, ao longo do período de 36 anos. Os resultados permitem visualizar as distintas dinâmicas regionais e sua interação com as dinâmicas setoriais.

Palavras-chave: Agropecuária. Rio Grande do Sul. Análise espacial.

\footnotetext{
* Doutor em Desenvolvimento Regional pela Universidade de Santa Cruz do Sul (Unisc) e professor do Departamento de Ciências Administrativas, Contábeis, Econômicas e da Comunicação da Universidade Regional do Noroeste do Estado do Rio Grande do Sul (Unijuî). E-mail: dilson@unijui. edu.br

** Doutorando em Geografia pelo Instituto de Geografia e Ordenamento do Território da Universidade de Lisboa. Professor da Universidade Estadual do Oeste do Paraná (Unioeste). Pesquisador do Grupo de Pesquisas em Desenvolvimento Regional e Agronegócio (Gepec). Bolsista Capes (Proc. nº BEX 1007/12-2). E-mail: lucir_a@hotmail.com

*** Doutor em Desenvolvimento Regional pela Universidade de Santa Cruz do Sul (Unisc) e professor da Universidade Regional Integrada (URI). E-mail: flores@fw.uri.br
} 
Abstract: In this article are presented the results of the analysis undertaken of the development of VBPA - Municipal Gross Value of Agricultural Production in Rio Grande do Sul, during the period 1970 until 2006. The data of the VBPA of 1970 were obtained directly from the agricultural census of 1970 and updated monetarily by IGP-DI for real values in 2006 and the data for the VBPA of 2006, obtained from agricultural census of 2006, through Sidra/IBGE, were converted to the same territorial basis of the municipalities of 1970, through the conversion system (PAIVA, 2007) using the criterion of the municipal area. With such procedures have become comparable data, expressed in the same currency, and referenced on municipal units with the same territorial area. Performance analyses were made of all municipalities and of the ten major agricultural activities, throughout this period of 36 years. The results allow you to view the different regional dynamics and its interaction with the activities dynamics.

Keywords: Agriculture. Rio Grande do Sul. Spatial analysis.

JEL Classification: R11.

\section{Introdução}

As desigualdades regionais do Rio Grande do Sul podem ser observadas sob diversas perspectivas. À heterogeneidade de suas características naturais (topografia, solos, clima, vegetação, etc.) foram acrescidas especificidades do processo de ocupação do território, povoamento e estruturação econômica. O processo de desenvolvimento socioeconômico, longe de constituir-se numa evolução natural homogeneizante, apresenta dinâmicas muito distintas em que se combinam e se confrontam os elementos constituintes dos diversos espaços e territórios.

Chamar a atenção para essa heterogeneidade seria apenas reafirmar o óbvio. Pouco acrescentaria a demonstração sobre a complexidade dessa realidade ou sobre as dificuldades de abordá-la sem correr riscos de demasiada simplificação. Entretanto, estar atento às dificuldades não implica submeter-se a estas. Cada esforço realizado no sentido de melhor compreender essa complexa realidade poderá contribuir para o aperfeiçoamento das ações humanas empreendidas com o objetivo de interferir nos rumos do futuro do estado.

O período compreendido entre 1970 e 2006 é particularmente rico em termos de elementos transformadores da realidade. Parte-se de um contexto em que os "governos da revolução" estavam concluindo seu trabalho de "arrumar a casa" e preparavam as ações que produziram o Milagre Brasileiro. A modernização da agropecuária brasileira havia sido iniciada em algumas atividades e em poucas regiões, ainda com reduzida influência nas estatísticas oficiais. Além do monumental impacto que esses dois fenômenos produziram, especialmente na década de 1970, 
novos fenômenos, como o acelerado progresso científico-tecnológico, a abertura da economia brasileira aos mercados mundiais, a integração agroindustrial, o avanço da fronteira agrícola nacional, a financeirização da economia e as mudanças na política econômica, entre outros, produziram efeitos sobre as dinâmicas de desenvolvimento locais e regionais.

De outra parte, as dificuldades metodológicas para analisar os dados municipais e regionais do Rio Grande do Sul relativos a esse período histórico eram enormes, desencorajando os pesquisadores menos estruturados. $\mathrm{O}$ acelerado processo de emancipações político-administrativas e a criação de inúmeros municípios com áreas desmembradas de diversos municípios-mãe tornaram praticamente impossível a tarefa de comparar os dados municipais e regionais num lapso temporal maior. A elaboração de um sistema de conversão ${ }^{1}$ de dados que possibilita a superação de tais dificuldades e a expectativa de compreender as dinâmicas setoriais e regionais de desenvolvimento motivaram a elaboração de estudos nessa direção e a sua atualização através do presente trabalho.

Assim, o objetivo deste artigo é socializar as principais constatações feitas na análise sobre a evolução do Valor Bruto da Produção Agropecuária (VBPA) dos municípios gaúchos no período de 1970 a 2006. Partindo de uma base de dados existentes (censos do IBGE), utilizando o sistema de conversão para possibilitar a comparação dos mesmos, foi feita a análise do desempenho dos municípios e dos principais produtos agropecuários em termos de evolução do VBPA ao longo do período de 36 anos.

O VBPA foi escolhido como indicador de desempenho municipal, regional e setorial a ser analisado em sua evolução histórica por duas razões básicas: por sua simplicidade e abrangência. O VBPA é composto pelo volume físico produzido em cada município multiplicado pelo preço médio da produção. Portanto, na impossibilidade de agregar os dados da produção física, o indicador mais simples em que seja possível tornar comensuráveis os dados sobre a agropecuária dos municípios do estado é o VBPA. De outra parte, sua capacidade explicativa também é limitada, embora não desprezível, pois não permite distinguir entre o consumo intermediário e o valor agregado, contidos no valor bruto da produção.

Os procedimentos utilizados neste estudo são muito simples. Os dados relativos ao VBPA dos municípios do Rio Grande do Sul em 1970 foram obtidos diretamente no Censo Agropecuário de 1970 e atualizados monetariamente pelo Índice Geral de Preços - Disponibilidade Interna (IGP-DI) para valores em reais de 2006. Já os dados referentes ao VBPA de 2006, obtidos do Censo Agropecuário de 2006, através do Sistema IBGE de Recuperação Automática (Sidra), foram convertidos

O sistema de conversão de dados foi elaborado pelo prof. Carlos Paiva e pode ser obtido em Paiva (2007). 
para a mesma base territorial dos municípios de 1970, através do sistema de conversão (PAIVA, 2007), utilizando o critério de área municipal. Nos casos em que são utilizados dados de períodos intermediários, como os do Censo Agropecuário de 1996, foram necessários ambos os procedimentos: de conversão, para a base municipal de 1970, e de atualização monetária para 2006. Com tais procedimentos, os dados tornaram-se comensuráveis, pois se tornaram expressos na mesma unidade monetária (em reais, de 2006), e também referenciados às unidades municipais com a mesma área territorial (malha de 1970).

$\mathrm{Na}$ análise dos dados foram observados os valores absolutos para cada município e sua evolução, bem como a concentração territorial $(\mathrm{R} \$ / \mathrm{Km} 2)$ através da divisão do VBPA pela área total do respectivo município e sua evolução no período. A pergunta básica, orientadora de toda a análise, foi formulada no sentido de identificar o que aconteceu nesse lapso de tempo. Fazer constatações sobre esse conjunto de informações é o alcance deste estudo, pois as perguntas sobre as causas ou as razões que produziram tais comportamentos exigiriam outro esforço de investigação, muito mais complexo.

\section{Evolução do VBPA do Rio Grande do Sul entre 1970 e 2006}

A observação dos dados sobre o VBPA municipal do Rio Grande do Sul em três momentos históricos distintos possibilita uma série de constatações relevantes. Superados os obstáculos à comparabilidade das informações municipais entre 1970, 1996 e 2006, podem-se realizar análises em distintas perspectivas e identificar comportamentos específicos de produtos ou setores econômicos e de municípios ou regiões do estado.

O VBPA total do estado, que em 1970 era de $\mathrm{R} \$ 13,258$ bilhões (valores corrigidos para 2006), apresentou um crescimento real de $25,9 \%$ no período de 36 anos e atingiu o montante de $\mathrm{R} \$ 16,693$ bilhões em 2006. Na decomposição desses dados, fica evidente a heterogeneidade setorial e regional do ritmo de crescimento.

Conforme os dados apresentados no Gráfico 1, enquanto algumas atividades que já eram importantes em 1970, como a soja e o arroz, apresentaram um crescimento superior à média e ampliaram sua participação em 2006, outras atividades, como a produção de trigo, de animais grandes e médios, apresentaram perdas em sua participação relativa. Produtos cuja expressão econômica era pequena em 1970, como o fumo, a lavoura permanente, a silvicultura e a atividade de aves e pequenos animais, incrementaram sua participação relativa no VBPA de 2006, graças ao acelerado crescimento registrado no período. 
Gráfico 1 - Composição setorial do VBPA municipal em 1970, 1996 e 2006 (percentual)

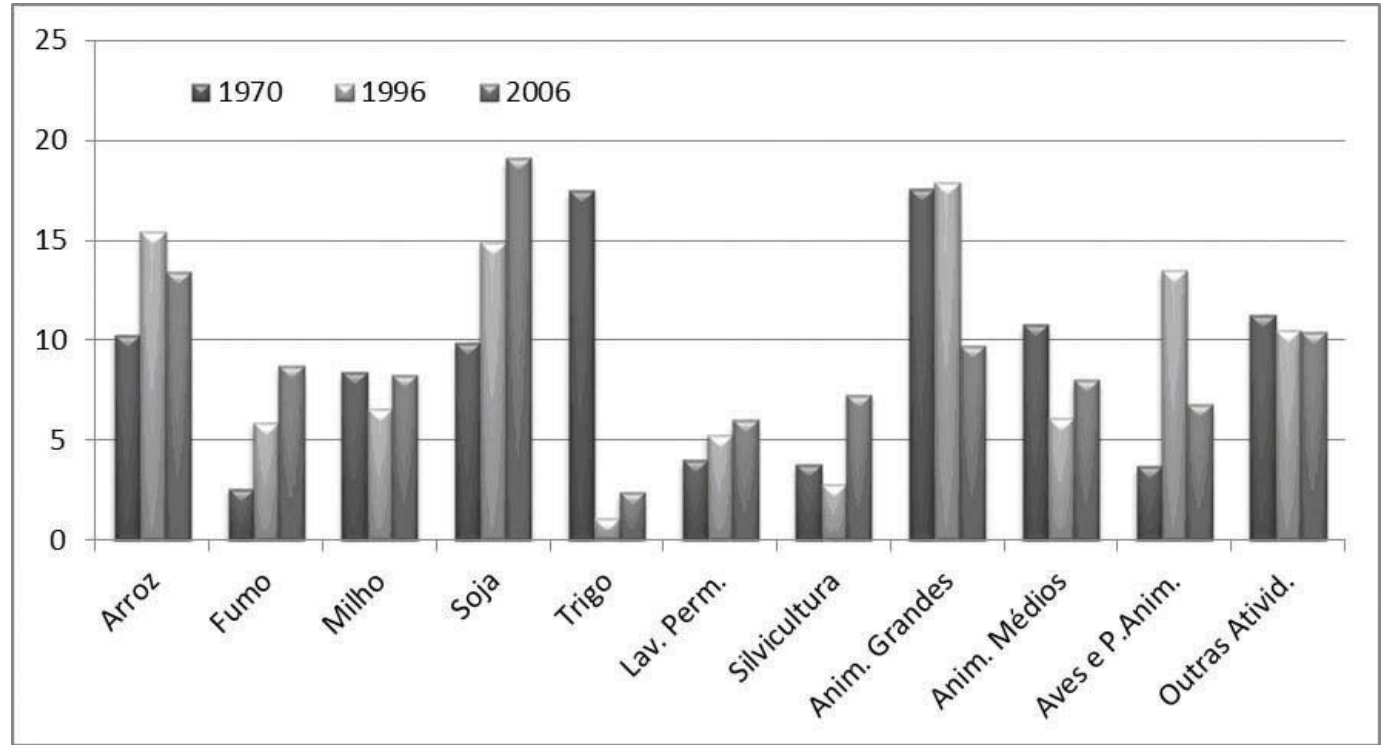

Fonte: Elaboração própria a partir de IBGE - Censos Agropecuários de 1970, 1996 e 2006.

Para este estudo foram selecionadas 10 atividades agropecuárias (produtos ou grupos), cuja participação no VBPA de 1970 era mais importante ou cuja especificidade local e regional fosse interessante de ser observada. Essas dez atividades, cuja análise de sua evolução será apresentada mais adiante, representavam 88,7\% do VBPA de 1970, num montante de R $\$ 11,76$ bilhões. Todas as demais atividades foram agregadas em outras atividades, com um valor bruto de $\mathrm{R} \$ 1,5$ bilhão ou $11,3 \%$ do VBPA. Ao longo do período de 36 anos, o valor bruto das dez atividades selecionadas cresceu $27,2 \%$, alcançando $\mathrm{R} \$ 14,95$ bilhões, enquanto o valor bruto das outras atividades cresceu 16,2\% e atingiu a cifra de $R \$ 1,74$ bilhão, além de sua participação ter caído para 10,4\% do VBPA municipal total.

Figura 1 - Valor bruto da produção agropecuária municipal total (1970 e 2006)

Valor da produção $/ \mathrm{Km}^{2}$ (1970)

Valor da produção/ $\mathrm{Km}^{2}$ (2006)
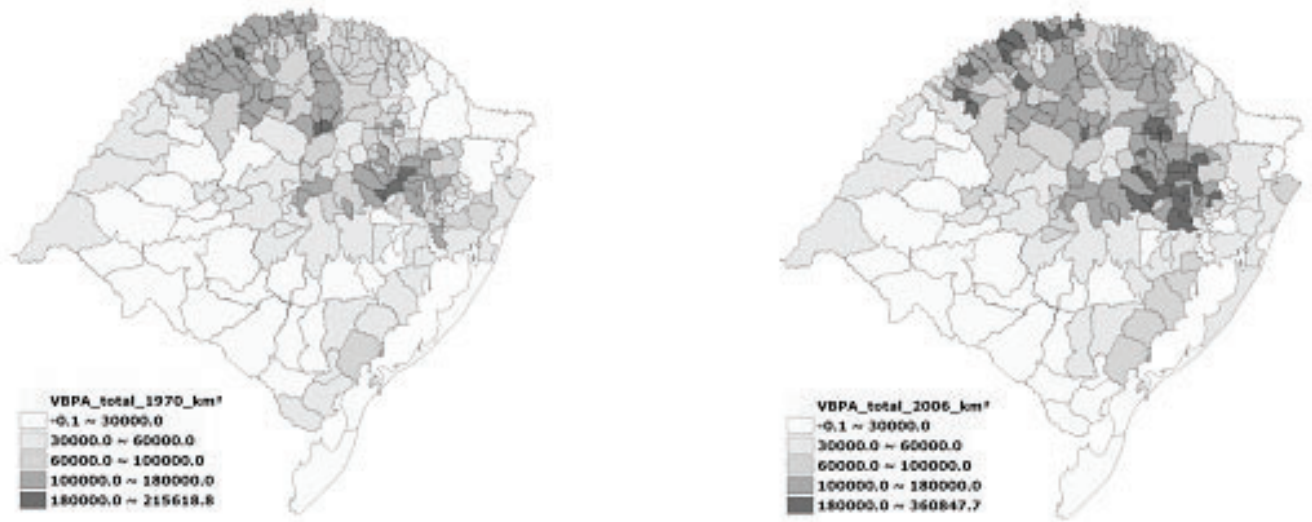

Fonte: Elaboração própria a partir de IBGE - Censos Agropecuários de 1970 e 2006.

TRENNEPOHL, D.; ALVES, L. R.; FLORES, A. J. Características Regionais da Evolução... 
Situações semelhantes podem ser apontadas em relação ao desempenho dos municípios e regiões do estado, especialmente quando os dados são tomados em sua densidade geográfica (VBPA/Km2). Enquanto os municípios localizados entre a Serra e o Nordeste apresentaram elevado crescimento absoluto e ampliaram seu peso relativo no VBPA estadual, os municípios da região metropolitana, entre outros, demonstraram redução acentuada em seus valores. Em diversos casos podem ser constatados comportamentos em sentidos opostos, em que o crescimento do valor produzido por um produto é compensado pela perda no valor produzido por outro produto, no mesmo município. Portanto, podem ser observadas as múltiplas combinações possíveis entre as variáveis em análise, configurando quadros específicos de desempenho setorial e regional.

Portanto, uma série de constatações pode ser feita com relativa facilidade e a reflexão sobre as mesmas possibilita a elaboração de hipóteses explicativas sobre a dinâmica de evolução do VBPA municipal do Rio Grande do Sul, em que se combinam trajetórias regionais com especificidades setoriais. A expectativa deste artigo é contribuir com tal reflexão.

\section{Especificidades Municipais e Regionais na Evolução do VBPA}

A observação dos dados sobre o VBPA municipal do Rio Grande do Sul pode ser feita sob diversos ângulos. A seguir são apresentados os principais resultados obtidos em relação às especificidades municipais. O objetivo é identificar os municípios que se destacam positiva ou negativamente em termos de evolução de seu VBPA.

Um primeiro olhar está direcionado aos dez municípios com maior VBPA do estado em 1970, conforme consta na Tabela 1. São municípios de grande porte, em termos de área territorial, e as atividades agropecuárias que lhes proporcionam valores de produção elevados são o trigo, os animais de grande porte e o arroz, que ocupam, no geral, vastas extensões de terra. Somente o município de Pelotas é que apresenta uma composição mais diversificada de seu VBPA, com forte participação das outras atividades. 
Tabela 1 - Os dez municípios com maior VBPA em 1970

\begin{tabular}{|c|c|c|c|c|c|c|}
\hline Descrição & $\begin{array}{c}\text { VBPA } \\
1970 \\
\text { R\$ mil }\end{array}$ & $\begin{array}{c}\text { VBPA } \\
1996 \\
\text { R\$ mil }\end{array}$ & $\begin{array}{c}\text { VBPA } 2006 \\
\text { R\$ mil }\end{array}$ & $\begin{array}{c}\text { Diferença } \\
\text { R\$ mil }\end{array}$ & $\begin{array}{c}\text { Evolução } \\
\%\end{array}$ & $\begin{array}{c}\text { Contribuição } \\
\%\end{array}$ \\
\hline Santo Ângelo & 255.090 & 198.503 & 215.918 & -39.172 & $-15,4 \%$ & $-1,1 \%$ \\
\hline São Borja & 248.268 & 200.557 & 177.491 & -70.777 & $-28,5 \%$ & $-2,1 \%$ \\
\hline Uruguaiana & 218.389 & 333.798 & 216.448 & -1.941 & $-0,9 \%$ & $-0,1 \%$ \\
\hline $\begin{array}{l}\text { Palmeira das } \\
\text { Missões }\end{array}$ & 218.052 & 189.404 & 227.711 & 9.659 & $4,4 \%$ & $0,3 \%$ \\
\hline Pelotas & 207.309 & 176.314 & 201.939 & -5.370 & $-2,6 \%$ & $-0,2 \%$ \\
\hline Alegrete & 205.242 & 231.155 & 158.741 & -46.501 & $-22,7 \%$ & $-1,4 \%$ \\
\hline Passo Fundo & 199.381 & 201.049 & 196.617 & -2.764 & $-1,4 \%$ & $-0,1 \%$ \\
\hline $\begin{array}{c}\text { Cachoeira } \\
\text { do Sul }\end{array}$ & 194.642 & 248.844 & 252.801 & 58.159 & $29,9 \%$ & $1,7 \%$ \\
\hline Itaqui & 181.950 & 248.209 & 246.886 & 64.936 & $35,7 \%$ & $1,9 \%$ \\
\hline Cruz Alta & 176.593 & 252.326 & 299.465 & 122.872 & $69,6 \%$ & $3,6 \%$ \\
\hline
\end{tabular}

Fonte: Elaboração própria a partir de IBGE - Censos Agropecuários de 1970, 1996 e 2006.

É interessante observar que, dentre os dez municípios com maior VBPA em 1970, seis apresentaram redução do seu valor ao longo do período. Alguns foram claramente afetados pela enorme queda no valor da produção de trigo, enquanto outros apresentaram redução significativa no valor da pecuária de grande ou médio porte. Outros, ainda, mal conseguiram compensar as perdas do trigo ou da pecuária com o crescimento da soja, da produção de aves e de outras atividades. 
Tabela 2 - Os dez municípios com maior VBPA em 2006

\begin{tabular}{|c|c|c|c|c|c|c|}
\hline Descrição & $\begin{array}{l}\text { VBPA } 1970 \\
\text { R\$ mil }\end{array}$ & $\begin{array}{c}\text { VBPA } 1996 \\
\text { R\$ mil }\end{array}$ & $\begin{array}{l}\text { VBPA } 2006 \\
\text { R\$ mil }\end{array}$ & $\begin{array}{c}\text { Diferença } \\
\text { R\$ mil }\end{array}$ & $\begin{array}{c}\text { Evolução } \\
\%\end{array}$ & $\begin{array}{c}\text { Contribuição } \\
\%\end{array}$ \\
\hline $\begin{array}{c}\text { Santa Cruz } \\
\text { do Sul }\end{array}$ & 168.554 & 239.377 & 304.541 & 135.987 & $80,7 \%$ & $4,0 \%$ \\
\hline Cruz Alta & 176.593 & 252.326 & 299.465 & 122.872 & $69,6 \%$ & $3,6 \%$ \\
\hline Vacaria & 117.363 & 301.003 & 280.654 & 163.291 & $139,1 \%$ & $4,8 \%$ \\
\hline Tupanciretã & 118.485 & 182.911 & 258.456 & 139.971 & $118,1 \%$ & $4,1 \%$ \\
\hline $\begin{array}{c}\text { Cachoeira } \\
\text { do Sul }\end{array}$ & 194.642 & 248.844 & 252.801 & 58.159 & $29,9 \%$ & $1,7 \%$ \\
\hline Itaqui & 181.950 & 248.209 & 246.886 & 64.936 & $35,7 \%$ & $1,9 \%$ \\
\hline Montenegro & 83.809 & 105.523 & 244.424 & 160.615 & $191,6 \%$ & $4,7 \%$ \\
\hline $\begin{array}{c}\text { São } \\
\text { Francisco de } \\
\text { Paula }\end{array}$ & 53.799 & 76.084 & 231.573 & 177.774 & $330,4 \%$ & $5,2 \%$ \\
\hline $\begin{array}{l}\text { Palmeira das } \\
\text { Missões }\end{array}$ & 218.052 & 189.404 & 227.711 & 9.659 & $4,4 \%$ & $0,3 \%$ \\
\hline Uruguaiana & 218.389 & 333.798 & 216.448 & -1.941 & $-0,9 \%$ & $-0,1 \%$ \\
\hline
\end{tabular}

Fonte: Elaboração própria a partir de IBGE - Censos Agropecuários de 1970, 1996 e 2006.

Outro olhar interessante está direcionado aos dez municípios com maior VBPA do Rio Grande do Sul em 2006, conforme consta na Tabela 2. Continuam sendo principalmente municípios de grande porte, em termos de área territorial, mas já aparecem também municípios de médio porte (menos de $2.000 \mathrm{Km} 2$ ) e com atividades agropecuárias de caráter intensivo, especialmente o fumo, como é o caso de Santa Cruz do Sul. Além do impacto da produção de arroz em Uruguaiana e outros municípios, merece destaque o efeito produzido pela produção de maçã em Vacaria e São Francisco de Paula, além da soja em Tupanciretã, Cruz Alta e Palmeira das Missões.

Vale ressaltar ainda que, para o ano de 2006, somente Uruguaiana e Palmeira das Missões apresentavam crescimento do VBPA inferior ao crescimento estadual, especialmente, devido às perdas com bovinos, ovinos e trigo. Os demais municípios contribuíram com $30 \%$ no crescimento do VBPA estadual. 
Tabela 3 - Os dez municípios com maior taxa de crescimento do VBPA entre 1970 e 2006

\begin{tabular}{|c|c|c|c|c|c|c|}
\hline Descrição & $\begin{array}{l}\text { VBPA } 1970 \\
\text { R\$ mil }\end{array}$ & $\begin{array}{l}\text { VBPA } 1996 \\
\text { R\$ mil }\end{array}$ & $\begin{array}{l}\text { VBPA } 2006 \\
\text { R\$ mil }\end{array}$ & $\begin{array}{c}\text { Diferença } \\
\text { R\$ mil }\end{array}$ & $\begin{array}{c}\text { Evoluçãa } \\
\%\end{array}$ & $\begin{array}{c}\text { Contribuição } \\
\%\end{array}$ \\
\hline Triunfo & 29.014 & 41.082 & 154.979 & 125.965 & $434,2 \%$ & $3,7 \%$ \\
\hline São & & & & & & \\
\hline $\begin{array}{l}\text { Francisco de } \\
\quad \text { Paula }\end{array}$ & 53.799 & 76.084 & 231.573 & 177.774 & $330,4 \%$ & $5,2 \%$ \\
\hline Ilópolis & 8.648 & 24.898 & 36.035 & 27.387 & $316,7 \%$ & $0,8 \%$ \\
\hline Nova Bréscia & 17.175 & 82.675 & 66.775 & 49.600 & $288,8 \%$ & $1,4 \%$ \\
\hline $\begin{array}{l}\text { Arroio dos } \\
\text { Ratos }\end{array}$ & 3.598 & 7.246 & 12.869 & 9.271 & $257,6 \%$ & $0,3 \%$ \\
\hline Piratini & 47.951 & 45.678 & 163.151 & 115.200 & $240,2 \%$ & $3,4 \%$ \\
\hline Ibiraiaras & 19.405 & 38.230 & 63.976 & 44.571 & $229,7 \%$ & $1,3 \%$ \\
\hline $\begin{array}{c}\text { São } \\
\text { Jerônimo }\end{array}$ & 26.114 & 65.133 & 83.499 & 57.385 & $219,7 \%$ & $1,7 \%$ \\
\hline $\begin{array}{c}\text { Nova } \\
\text { Bassano }\end{array}$ & 19.863 & 78.544 & 59.949 & 40.086 & $201,8 \%$ & $1,2 \%$ \\
\hline Paraí & 14.038 & 28.560 & 41.044 & 27.006 & $192,4 \%$ & $0,8 \%$ \\
\hline
\end{tabular}

Fonte: Elaboração própria a partir de IBGE - Censos Agropecuários de 1970, 1996 e 2006.

Quando o olhar é direcionado aos dez municípios com os maiores índices de crescimento de seu VBPA no período, os destaques passam a ser outros, conforme mostra a Tabela 3. Aparecem municípios cuja base de cálculo é muito pequena e cujo crescimento modesto em termos absolutos proporciona um elevado percentual de incremento, como é o caso de Arroio dos Ratos e Ilópolis. Mas também são perceptíveis os municípios com crescimento vigoroso sobre uma base de importância significativa, como é o caso de Triunfo, São Francisco de Paula e Piratini. Em todos, podem ser detectadas atividades, como a silvicultura, com ritmo de crescimento acelerado, que modificaram substancialmente as características da produção agropecuária municipal no período.

Ao focar pelo ângulo dos dez municípios com maior redução em seu VBPA no período, aparecem os casos situados no outro extremo, de acordo com o que consta na Tabela 4. São municípios cujo desempenho foi afetado negativamente em dimensões muito significativas.

A maior parte desses municípios está situada na região metropolitana da capital do estado e seu VBPA já era pouco expressivo em 1970. O crescimento populacional que ocorreu nesse lapso de tempo provocou uma ampliação das áreas urbanas e suburbanas desses municípios, que pode ter afetado diretamente os espaços anteriormente destinados à produção agropecuária. Há também os 
casos de Pinheiro Machado e Lavras do Sul, cuja redução ocorreu nas atividades da pecuária, mesmo sem registrar perdas de área destinada à agropecuária.

Tabela 4 - Os dez municípios com maior redução percentual de seu VBPA entre 1970 e 2006

\begin{tabular}{|c|c|c|c|c|c|c|}
\hline Descrição & $\begin{array}{c}\text { VBPA } 1970 \\
\text { R\$ mil }\end{array}$ & $\begin{array}{c}\text { VBPA } 1996 \\
\text { R\$ mil }\end{array}$ & $\begin{array}{c}\text { VBPA } 2006 \\
\text { R\$ mil }\end{array}$ & $\begin{array}{c}\text { Diferença } \\
\text { R\$ mil }\end{array}$ & $\begin{array}{c}\text { Evolução } \\
\%\end{array}$ & $\begin{array}{c}\text { Contribuição } \\
\%\end{array}$ \\
\hline Cachoeirinha & 6.549 & 515 & 593 & -5.956 & $-90,9 \%$ & $-0,2 \%$ \\
\hline Alvorada & 3.662 & 1.765 & 449 & -3.213 & $-87,7 \%$ & $-0,1 \%$ \\
\hline Porto Alegre & 66.891 & 54.571 & 11.179 & -55.712 & $-83,3 \%$ & $-1,6 \%$ \\
\hline São Leopoldo & 4.387 & 2.313 & 752 & -3.635 & $-82,9 \%$ & $-0,1 \%$ \\
\hline $\begin{array}{l}\text { Pinheiro } \\
\text { Machado }\end{array}$ & 47.864 & 31.131 & 11.127 & -36.737 & $-76,8 \%$ & $-1,1 \%$ \\
\hline Lavras do Sul & 55.016 & 28.336 & 13.125 & -41.891 & $-76,1 \%$ & $-1,2 \%$ \\
\hline Gravataí & 69.586 & 36.007 & 20.165 & -49.421 & $-71,0 \%$ & $-1,4 \%$ \\
\hline Canela & 12.477 & 7.851 & 3.824 & -8.653 & $-69,4 \%$ & $-0,3 \%$ \\
\hline Gramado & 19.735 & 13.714 & 6.315 & -13.420 & $-68,0 \%$ & $-0,4 \%$ \\
\hline Campo Bom & 3.031 & 636 & 970 & -2.061 & $-68,0 \%$ & $-0,1 \%$ \\
\hline
\end{tabular}

Fonte: Elaboração própria a partir de IBGE - Censos Agropecuários de 1970 e 1996.

Um olhar muito interessante é aquele direcionado aos dez municípios com a maior contribuição para o crescimento do VBPA do Rio Grande do Sul entre 1970 e 2006, de acordo com os dados que constam na Tabela 5. São municípios de grande porte econômico e cujas atividades agropecuárias tiveram crescimento significativo, o que lhes proporcionou aumento significativo nos valores de produção e impactos relevantes nos totais do estado.

Juntos, esses dez municípios representam $38,10 \%$ do montante de aumento do VBPA do estado no período. Cada um deles contribuiu com parcelas superiores a 2,3\%, chegando a 5,2\% no caso de São Francisco de Paula. O excelente desempenho desses municípios está associado às atividades predominantes que compõem o seu VBPA. Alguns exemplos são a lavoura permanente (maçã) e a silvicultura - responsáveis pelo desempenho de São Francisco de Paula, Vacaria, Montenegro, Triunfo e Piratini - a soja, que foi decisiva para Tupanciretã e Cruz Alta, o fumo, para Santa cruz do Sul, e a pecuária intensiva (leite, suínos e aves) para Nova Prata e Salvador do Sul. 
Tabela 5 - Os dez municípios com maior contribuição para o crescimento do VBPA do Rio Grande do Sul

\begin{tabular}{|c|c|c|c|c|c|c|}
\hline Descrição & $\begin{array}{l}\text { VBPA } 1970 \\
\text { R\$ mil }\end{array}$ & $\begin{array}{l}\text { VBPA } 1996 \\
\text { R\$ mil }\end{array}$ & $\begin{array}{l}\text { VBPA } 2006 \\
\text { R\$ mil }\end{array}$ & $\begin{array}{c}\text { Diferença } \\
\text { R\$ mil }\end{array}$ & $\begin{array}{c}\text { Evolução } \\
\%\end{array}$ & $\begin{array}{c}\text { Contribuição } \\
\%\end{array}$ \\
\hline $\begin{array}{c}\text { São } \\
\text { Francisco de } \\
\text { Paula }\end{array}$ & 53.799 & 76.084 & 231.573 & 177.774 & $330,4 \%$ & $5,2 \%$ \\
\hline Vacaria & 117.363 & 301.003 & 280.654 & 163.291 & $139,1 \%$ & $4,8 \%$ \\
\hline Montenegro & 83.809 & 105.523 & 244.424 & 160.615 & $191,6 \%$ & $4,7 \%$ \\
\hline Tupanciretã & 118.485 & 182.911 & 258.456 & 139.971 & $118,1 \%$ & $4,1 \%$ \\
\hline $\begin{array}{c}\text { Santa Cruz } \\
\text { do Sul }\end{array}$ & 168.554 & 239.377 & 304.541 & 135.987 & $80,7 \%$ & $4,0 \%$ \\
\hline Triunfo & 29.014 & 41.082 & 154.979 & 125.965 & $434,2 \%$ & $3,7 \%$ \\
\hline Cruz Alta & 176.593 & 252.326 & 299.465 & 122.872 & $69,6 \%$ & $3,6 \%$ \\
\hline Piratini & 47.951 & 45.678 & 163.151 & 115.200 & $240,2 \%$ & $3,4 \%$ \\
\hline Nova Prata & 48.890 & 94.958 & 128.279 & 79.389 & $162,4 \%$ & $2,3 \%$ \\
\hline $\begin{array}{c}\text { Salvador do } \\
\text { Sul }\end{array}$ & 49.056 & 141.139 & 127.971 & 78.915 & $160,9 \%$ & $2,3 \%$ \\
\hline
\end{tabular}

Fonte: Elaboração própria a partir de IBGE - Censos Agropecuários de 1970, 1996 e 2006.

No sentido inverso, é o olhar direcionado aos dez municípios com maior redução absoluta em seu VBPA no período e, portanto, com contribuição negativa para o crescimento do total do estado, em conformidade com a Tabela 6. São municípios de porte econômico relevante, cujas atividades agropecuárias que compõem seus valores de produção tiveram desempenhos negativos por distintas circunstâncias. 
Tabela 6 - Os dez municípios com maior redução absoluta do seu VBPA do Rio Grande do Sul

\begin{tabular}{|c|c|c|c|c|c|c|}
\hline Descrição & $\begin{array}{l}\text { VBPA } 1970 \\
\text { R\$ mil }\end{array}$ & $\begin{array}{l}\text { VBPA } 1996 \\
\text { R\$ mil }\end{array}$ & $\begin{array}{l}\text { VBPA } 1996 \\
\text { R\$ mil }\end{array}$ & $\begin{array}{l}\text { Diferença } \\
\text { R\$ mil }\end{array}$ & $\begin{array}{c}\text { Evolução } \\
\%\end{array}$ & $\begin{array}{c}\text { Contribuição } \\
\%\end{array}$ \\
\hline $\begin{array}{l}\text { Santana do } \\
\text { Livramento }\end{array}$ & 147.079 & 125.763 & 59.939 & -87.140 & $-59,2 \%$ & $-2,5 \%$ \\
\hline Bagé & 174.488 & 162.620 & 94.176 & -80.312 & $-46,0 \%$ & $-2,3 \%$ \\
\hline São Borja & 248.268 & 200.557 & 177.491 & -70.777 & $-28,5 \%$ & $-2,1 \%$ \\
\hline Giruá & 161.662 & 91.907 & 100.315 & -61.347 & $-37,9 \%$ & $-1,8 \%$ \\
\hline Porto Alegre & 66.891 & 54.571 & 11.179 & -55.712 & $-83,3 \%$ & $-1,6 \%$ \\
\hline Gravataí & 69.586 & 36.007 & 20.165 & -49.421 & $-71,0 \%$ & $-1,4 \%$ \\
\hline Alegrete & 205.242 & 231.155 & 158.741 & -46.501 & $-22,7 \%$ & $-1,4 \%$ \\
\hline $\begin{array}{l}\text { Lavras do } \\
\quad \text { Sul }\end{array}$ & 55.016 & 28.336 & 13.125 & -41.891 & $-76,1 \%$ & $-1,2 \%$ \\
\hline $\begin{array}{l}\text { Santo } \\
\text { Ângelo }\end{array}$ & 255.090 & 198.503 & 215.918 & -39.172 & $-15,4 \%$ & $-1,1 \%$ \\
\hline $\begin{array}{l}\text { Pinheiro } \\
\text { Machado }\end{array}$ & 47.864 & 31.131 & 11.127 & -36.737 & $-76,8 \%$ & $-1,1 \%$ \\
\hline
\end{tabular}

Fonte: Elaboração própria a partir de IBGE - Censos Agropecuários de 1970 e 1996.

Há que se destacar a importância da pecuária extensiva e do trigo na composição do VBPA da maior parte desses municípios e no seu desempenho extremamente negativo. Os piores desempenhos foram registrados pelos municípios de Santana do Livramento, Bagé e São Borja, em que a bovinocultura e a ovinocultura têm maior peso na composição do valor. Em alguns municípios, o desempenho positivo da soja compensou a queda do trigo, mas em outros, como Giruá, Santo Ângelo e São Borja, isso não foi suficiente. A redução do VBPA nos municípios de Porto Alegre e Gravataí ocorreu em diversas atividades, o que pode estar indicando a destinação de áreas para outras atividades e a redução do espaço da agropecuária para a ocupação urbana.

Além de observar os dados absolutos sobre os municípios gaúchos, foi feita também uma análise relativa à densidade econômica nos diversos espaços. Para tanto, foram considerados os dados de valor da produção divididos pela área territorial de cada município em 1970, constituindo as informações de VBPA em R\$/ $\mathrm{Km}^{2}$ para o mesmo período.

Seguindo caminho semelhante ao procedimento anterior, um primeiro olhar é direcionado aos dez municípios com o maior VBPA $/ \mathrm{Km}^{2}$ do Rio Grande do Sul em 1970, conforme consta na Tabela 7. São municípios de menor porte, em termos de área territorial, mas com atividades agropecuárias que lhes proporcionam valores de produção elevados, como o suíno, em Boa Vista do Buricá, Estrela e 
Cruzeiro do Sul, a uva, em Garibaldi, e o trigo, complementado pela soja, em Tapera, Selbach, Miraguaí e Não-me-Toque.

Tabela 7 - Os dez municípios com maior VBPA/Km em 1970

\begin{tabular}{|c|c|c|c|c|c|c|c|}
\hline Descrição & $\begin{array}{c}\text { VBPA } \\
1970 \\
\text { R\$ mil }\end{array}$ & $\begin{array}{c}\text { VBPA } \\
1996 \\
\text { R\$ mil }\end{array}$ & $\begin{array}{c}\text { VBPA } \\
2006 \\
\text { R\$ mil }\end{array}$ & $\begin{array}{c}\text { VBPA } \\
1970 \\
\mathbf{R} \$ / \mathbf{K m 2}\end{array}$ & $\begin{array}{c}\text { VBPA } \\
1996 \\
\mathrm{R} \$ \mathbf{K m} 2\end{array}$ & $\begin{array}{c}\text { VBPA } \\
2006 \\
\text { R\$/Km2 }\end{array}$ & $\begin{array}{c}\text { Evolução } \\
2006 / 70 \\
\%\end{array}$ \\
\hline $\begin{array}{l}\text { Boa Vista } \\
\text { do Buricá }\end{array}$ & 40.767 & 30.068 & 42.007 & 215.619 & 159.029 & 222.177 & $3,0 \%$ \\
\hline Garibaldi & 70.579 & 151.564 & 106.888 & 191.266 & 410.732 & 289.662 & $51,4 \%$ \\
\hline Tapera & 46.592 & 34.715 & 43.235 & 186.885 & 139.244 & 173.419 & $-7,2 \%$ \\
\hline Estrela & 93.591 & 165.233 & 158.967 & 186.189 & 328.710 & 316.245 & $69,9 \%$ \\
\hline $\begin{array}{c}\text { Cruzeiro } \\
\text { do Sul }\end{array}$ & 28.729 & 38.519 & 43.933 & 184.942 & 247.965 & 282.818 & $52,9 \%$ \\
\hline Selbach & 32.475 & 27.723 & 35.014 & 181.189 & 154.678 & 195.358 & $7,8 \%$ \\
\hline Miraguaí & 21.936 & 11.149 & 11.590 & 172.887 & 87.867 & 91.346 & $-47,2 \%$ \\
\hline $\begin{array}{c}\text { Não-me- } \\
\text { Toque }\end{array}$ & 72.953 & 59.408 & 66.447 & 167.890 & 136.718 & 152.917 & $-8,9 \%$ \\
\hline $\begin{array}{l}\text { Santo } \\
\text { Cristo }\end{array}$ & 62.427 & 76.031 & 68.842 & 164.400 & 200.224 & 181.292 & $10,3 \%$ \\
\hline
\end{tabular}

Fonte: Elaboração própria a partir de IBGE - Censos Agropecuários de 1970, 1996 e 2006.

É importante destacar que, dentre os dez municípios selecionados, três tiveram redução de seu VBPA no período, especialmente aqueles que possuíam uma participação expressiva do trigo em sua produção. Outros três cresceram em ritmo acelerado, superior a media estadual, especialmente pela expansão da avicultura.

Um olhar complementar é o que está direcionado aos dez municípios com o maior VBPA $/ \mathrm{Km}^{2}$ em 2006, conforme apontado na Tabela 8. Mais ainda, aparecem os municípios de menor porte, em termos de área territorial, mas com atividades agropecuárias altamente concentradas e que lhes proporcionam valores de produção elevados, como é o caso da avicultura, da uva, do leite e de outras atividades agropecuárias. 
Tabela 8 - Os dez municípios com maior VBPA/Km² em 2006

\begin{tabular}{|c|c|c|c|c|c|c|c|}
\hline Descrição & $\begin{array}{c}\text { VBPA } \\
1970 \\
\text { R\$ mil }\end{array}$ & $\begin{array}{c}\text { VBPA } \\
1996 \\
\text { R\$ mil }\end{array}$ & $\begin{array}{c}\text { VBPA } \\
2006 \\
\text { R\$ mil }\end{array}$ & $\begin{array}{c}\text { VBPA } \\
1970 \\
\text { R\$/Km2 }\end{array}$ & $\begin{array}{c}\text { VBPA } \\
1996 \\
\text { R\$/Km2 }\end{array}$ & $\begin{array}{c}\text { VBPA } \\
2006 \\
\text { R\$/Km2 }\end{array}$ & $\begin{array}{c}\text { Evolução } \\
2006 / 70 \\
\%\end{array}$ \\
\hline $\begin{array}{l}\text { Salvador do } \\
\text { Sul }\end{array}$ & 49.056 & 141.139 & 127.971 & 138.327 & 397.979 & 360.848 & $160,9 \%$ \\
\hline Nova Araçá & 6.629 & 21.871 & 17.851 & 128.928 & 425.334 & 347.161 & $169,3 \%$ \\
\hline Paraí & 14.038 & 28.560 & 41.044 & 114.893 & 233.750 & 335.931 & $192,4 \%$ \\
\hline $\begin{array}{l}\text { Nova } \\
\text { Bréscia }\end{array}$ & 17.175 & 82.675 & 66.775 & 82.356 & 396.446 & 320.202 & $288,8 \%$ \\
\hline Estrela & 93.591 & 165.233 & 158.967 & 186.189 & 328.710 & 316.245 & $69,9 \%$ \\
\hline Montenegro & 83.809 & 105.523 & 244.424 & 107.602 & 135.480 & 313.815 & $191,6 \%$ \\
\hline Ilópolis & 8.648 & 24.898 & 36.035 & 72.564 & 208.912 & 302.358 & $316,7 \%$ \\
\hline Garibaldi & 70.579 & 151.564 & 106.888 & 191.266 & 410.732 & 289.662 & $51,4 \%$ \\
\hline $\begin{array}{c}\text { Nova } \\
\text { Bassano }\end{array}$ & 19.863 & 78.544 & 59.949 & 94.974 & 375.557 & 286.645 & $201,8 \%$ \\
\hline
\end{tabular}

Fonte: Elaboração própria a partir de IBGE - Censos Agropecuários de 1970 e 1996.

Pode-se observar que houve crescimento expressivo no VBPA em todos os municípios apontados na Tabela 8, indicando que as características da produção foram redefinidas em grande medida ao longo do período em análise. Em todos há a participação significativa de duas ou mais atividades na configuração do valor. Somente dois municípios, Garibaldi e Estrela, constavam no rol dos dez maiores em 1970. Os demais conquistaram as altas densidades econômicas por incrementos superiores, sendo que quatro, Ilópolis, Nova Bréscia, Nova Bassano e Paraí, constam entre os dez municípios com maior taxa de crescimento no estado. Em todos pode ser percebida a presença da pecuária intensiva (aves, suínos e leite) e uma maior diversificação da produção.

Por fim, para concluir este conjunto de observações sobre as especificidades municipais de evolução do VBPA gaúcho, importa direcionar um olhar aos municípios com o menor VBPA/Km2 em 1970 e 2006, conforme consta nas Tabelas 9 e 10. 
Tabela 9 - Os dez municípios com menor VBPA/Km em 1970

\begin{tabular}{|c|c|c|c|c|c|c|c|}
\hline Descrição & $\begin{array}{c}\text { VBPA } \\
1970 \\
\text { R\$ mil }\end{array}$ & $\begin{array}{c}\text { VBPA } \\
1996 \\
\text { R\$ mil }\end{array}$ & $\begin{array}{c}\text { VBPA } \\
2006 \\
\text { R\$ mil }\end{array}$ & $\begin{array}{c}\text { VBPA } \\
1970 \\
\text { R\$/Km2 }\end{array}$ & $\begin{array}{c}\text { VBPA } \\
1996 \\
\text { R\$/Km2 }\end{array}$ & $\begin{array}{c}\text { VBPA } \\
2006 \\
\text { R\$/Km2 }\end{array}$ & $\begin{array}{c}\text { Evolução } \\
2006 / 70 \\
\%\end{array}$ \\
\hline $\begin{array}{c}\text { Cambará } \\
\text { do Sul }\end{array}$ & 8.212 & 51.072 & 20.319 & 6.930 & $3.099,35$ & $17.147,12$ & $147,4 \%$ \\
\hline $\begin{array}{c}\text { Arroio dos } \\
\text { Ratos }\end{array}$ & 3.598 & 7.246 & 12.869 & 8.416 & $16.947,64$ & $0.098,00$ & $257,6 \%$ \\
\hline Bom Jesus & 41.558 & 73.421 & 55.879 & 10.974 & $19.387,46$ & $14.755,40$ & $34,5 \%$ \\
\hline Tramandaí & 7.620 & 18.773 & 12.001 & 11.997 & $29.557,59$ & $18.895,64$ & $57,5 \%$ \\
\hline $\begin{array}{c}\text { Santana da } \\
\text { Boa Vista }\end{array}$ & 17.838 & 17.724 & 14.223 & 12.290 & $2.211,34$ & $9.799,50$ & $-20,3 \%$ \\
\hline Esmeralda & 16.703 & 24.974 & 36.721 & 12.814 & $19.158,52$ & $8.170,65$ & $119,8 \%$ \\
\hline $\begin{array}{c}\text { São } \\
\text { Francisco } \\
\text { de Paula }\end{array}$ & 53.799 & 76.084 & 231.573 & 13.598 & $19.231,49$ & $58.533,76$ & $330,4 \%$ \\
\hline Piratini & 47.951 & 45.678 & 163.151 & 14.365 & $13.684,39$ & $48.877,46$ & $240,2 \%$ \\
\hline Mostardas & 43.577 & 112.068 & 120.078 & 14.875 & $38.253,98$ & $40.988,27$ & $175,6 \%$ \\
\hline
\end{tabular}

Fonte: Elaboração própria a partir de IBGE - Censos Agropecuários de 1970 e 1996.

Tabela 10 - Os dez municípios com menor VBPA/Km em 2006

\begin{tabular}{|c|c|c|c|c|c|c|c|}
\hline Descrição & $\begin{array}{c}\text { VBPA } \\
1970 \\
\text { R\$ mil }\end{array}$ & $\begin{array}{c}\text { VBPA } \\
1996 \\
\text { R\$ mil }\end{array}$ & $\begin{array}{c}\text { VBPA } \\
2006 \\
\text { R\$ mil }\end{array}$ & $\begin{array}{c}\text { VBPA } \\
1970 \\
\text { R\$/Km2 }\end{array}$ & $\begin{array}{c}\text { VBPA } \\
1996 \\
\text { R\$/Km2 }\end{array}$ & $\begin{array}{c}\text { VBPA } \\
2006 \\
\text { R\$/Km2 }\end{array}$ & $\begin{array}{c}\text { Evolução } \\
2006 / 70 \\
\%\end{array}$ \\
\hline $\begin{array}{l}\text { Pinheiro } \\
\text { Machado }\end{array}$ & 47.864 & 31.131 & 11.127 & 15.951 & $10.374,60$ & $3.708,20$ & $-76,8 \%$ \\
\hline $\begin{array}{l}\text { Lavras do } \\
\text { Sul }\end{array}$ & 55.016 & 28.336 & 13.125 & 21.537 & $11.092,51$ & $5.137,93$ & $-76,1 \%$ \\
\hline Alvorada & 3.662 & 1.765 & 449 & 49.579 & $23.890,96$ & $6.078,25$ & $-87,7 \%$ \\
\hline $\begin{array}{c}\text { São } \\
\text { Leopoldo }\end{array}$ & 4.387 & 2.313 & 752 & 40.388 & $21.295,38$ & $6.923,86$ & $-82,9 \%$ \\
\hline $\begin{array}{l}\text { Santana do } \\
\text { Livramento }\end{array}$ & 147.079 & 125.763 & 59.939 & 21.213 & $18.138,71$ & $8.644,95$ & $-59,2 \%$ \\
\hline $\begin{array}{c}\text { Santana da } \\
\text { Boa Vista }\end{array}$ & 17.838 & 17.724 & 14.223 & 12.290 & $12.211,34$ & $9.799,50$ & $-20,3 \%$ \\
\hline Herval & 49.223 & 36.656 & 28.097 & 17.322 & $12.899,23$ & $\mathbf{9 . 8 8 7 , 3 9}$ & $-42,9 \%$ \\
\hline Quaraí & 64.007 & 54.786 & 40.000 & 19.656 & $16.824,05$ & $12.283,54$ & $-37,5 \%$ \\
\hline Bagé & 174.488 & 162.620 & 94.176 & 24.474 & $22.809,27$ & $13.209,25$ & $-46,0 \%$ \\
\hline
\end{tabular}

Fonte: Elaboração própria a partir de IBGE - Censos Agropecuários de 1970 e 1996.

Estes são municípios em que há uma baixa densidade econômica da produção agropecuária porque praticam atividades extensivas, como a pecuária de 
corte ou ovinocultura, nos anos 1970, ou porque destinaram grande parte de seu território às ocupações urbanas, como ocorre com diversos municípios da região metropolitana da capital do estado. Dos dez municípios em pior situação em 1970, nove apresentaram crescimento superior à média estadual no período e apenas Santana da Boa Vista regrediu em seu nível de produção.

Conforme mostra a Tabela 10, os dez municípios em pior posição em 2006 chegaram a tal situação devido ao seu desempenho extremamente negativo no período, com perdas superiores a $80 \%$ de seu VBPA em alguns casos. Com exceção dos municípios da região metropolitana, como Alvorada e São Leopoldo, cuja área rural é pequena, todos os demais municípios representam grandes vazios econômicos, com baixa densidade populacional e baixa produção agropecuária.

\section{Relações entre as Especificidades Regionais e Setoriais}

A observação dos dados sobre o VBPA municipal do Rio Grande do Sul em dois momentos históricos distintos, conforme feito anteriormente, possibilita fazer uma série de constatações relevantes sobre as dinâmicas setoriais e regionais de desenvolvimento da agropecuária.

Existem diversos movimentos que podem ser percebidos nesse período de tempo articulando características dos recursos naturais disponíveis nos municípios com especificidades técnicas das atividades agropecuárias num ambiente econômico e de mercado que compõem oportunidades e restrições ao desenvolvimento de cada território. Neste estudo foi possível detectar os movimentos a seguir.

\subsection{A Expansão da Pecuária Intensiva na Serra Gaúcha}

O movimento que gerou o maior impacto na evolução do VBPA do Rio Grande do Sul, em sua distribuição municipal e regional, foi o crescimento acelerado da produção de aves, suínos e leite, especialmente nos municípios da região da Serra. Essa região já possuía uma concentração econômica em 1970, e a expansão das atividades de produção animal contribuiu decisivamente para o incremento do VBPA em diversos municípios da região.

A avicultura (assim como a suinocultura e a pecuária leiteira) existente no Rio Grande do Sul até 1970 possuía características muito distintas das atuais. Predominavam as criações de quintal e praticamente todas as unidades agrícolas possuíam certo número de aves que exigiam poucos cuidados e forneciam pequenas quantidades de ovos e carne. Poucos municípios possuíam produtores que tinham a avicultura como uma atividade econômica, da qual pudessem obter sua renda. Posteriormente, a avicultura sofreu transformações importantes e foi organizada como atividade empresarial. Não foi propriamente uma evolução, mas muito 
mais a implantação de uma nova atividade, independente daquela que existia anteriormente.

A nova atividade apresenta características marcantes em relação ao grau de desenvolvimento tecnológico, de especialização e de integração dos diversos segmentos produtivos envolvidos. Dessa forma, a produção passou a ser feita em grande escala, viabilizando o emprego da tecnologia mais avançada existente no mundo.

Constitui característica da atividade a rápida concentração e centralização de capitais. Em poucos anos as grandes integradoras (Sadia, Perdigão, Frango Sul, Pena Branca, Minuano, etc.) conseguiram abarcar todos os segmentos produtivos sob sua direção e em grandes escalas de produção. Essas grandes empresas têm definido a dinâmica da atividade e sua expansão no estado e no país, possuindo elevado grau de influência nas instâncias governamentais. Os elementos fundamentais que contribuíram para a expansão da avicultura, da suinocultura e da pecuária leiteira no estado foram os ganhos de produtividade alcançados que permitiram a redução dos custos da carne e do leite ofertados no mercado brasileiro e a abertura do mercado internacional a partir de 1975 (para aves e suínos), com preços compensadores e demandas por quantidades ilimitadas para as possibilidades brasileiras.

Fundamentalmente a pecuária intensiva compreende atividades muito dinâmicas, conduzidas empresarialmente pelas empresas integradoras e que respondem rapidamente aos incentivos do mercado. Possuem grande capacidade competitiva frente aos demais produtores e continuam aumentando seu espaço e sua importância na economia do estado.

\subsection{A Inversão do Binômio Trigo-Soja no Planalto Gaúcho}

No planalto gaúcho ocorreram dois movimentos em sentidos opostos, ambos com grande impacto no VBPA do Rio Grande do Sul e em sua distribuição municipal e regional. Um deles é definido pela brutal queda no valor da produção de trigo, que deixou de ser a atividade agropecuária mais importante do estado $(17,5 \%$ em 1970) para contribuir com menos de $2 \%$ do total em 2006 . O outro, em sentido inverso, é o processo de expansão da soja cujo valor da produção cresceu de $10 \%$ para $19 \%$ do total estadual. Em nível de estado e de alguns municípios, houve certa compensação de um movimento por outro, mas é importante assinalar que a soja expandiu sua área em municípios que não produziam trigo ou produziam pouco e que a redução do valor da produção de trigo ocorreu em muitos municípios que já haviam ocupado suas terras com a soja em 1970 e, portanto, tinham poucas possibilidades para continuar a expansão.

Quando se imaginava que a triticultura gaúcha havia atingido um patamar de estabilidade e maturidade na produção, mesmo sob a tutela do governo fede- 
ral, sobretudo em relação ao mercado, o quadro sofreu uma alteração substancial. As mudanças na política agrícola oficial, nos anos 1990, especialmente com o fim do monopólio estatal de comercialização do trigo, colocaram em risco todo o esforço e os recursos públicos empregados durante muitos anos de valorização da triticultura nacional.

Além das incertezas climáticas, configurou-se um cenário de mercado completamente desfavorável com o fim da compra estatal do trigo e diante da concorrência do trigo importado, especialmente do Mercosul, com qualidade superior e preços acessíveis aos grandes consumidores de grãos, o que fez com que os preços caíssem acentuadamente. Em consequência, houve forte redução da área cultivada e da produção física.

Já a cultura da soja, introduzida no Brasil por imigrantes japoneses no início do século XX, somente adquire certa importância a partir dos anos 1950. No Rio Grande do Sul seu cultivo começou através dos colonos, na microrregião de Santa Rosa, visando atender o autoconsumo. O primeiro indício de comercialização do produto somente pode ser registrado em 1936, e pouco incremento houve nas duas décadas seguintes.

Com a expansão da triticultura, nas décadas de 50 e 60, a soja ganhou um importante espaço para crescer, aproveitando-se de toda a estrutura montada para o trigo. Enquanto cultura secundária, a soja utilizava, durante o verão, as mesmas áreas de terras, máquinas, equipamentos e força de trabalho que o trigo ocupava no inverno. As cooperativas tritícolas assumiram a comercialização da soja e aproveitaram os mesmos armazéns, silos, secadores, balanças e escritórios. Com duas safras por ano, a velocidade de rotação do capital empregado tornou-se muito maior. Formou-se assim o chamado "binômio trigo-soja", através do qual se produz uma profunda transformação na agropecuária do planalto gaúcho.

Porém, diferentemente do trigo, a soja não apresentou problemas de adequação às condições naturais de produção e não sofreu a concorrência do exterior. Além disso, o mercado internacional estava ávido pela soja brasileira e oferecia bons preços e pagamentos adiantados. Nessas condições, o crescimento da área colhida e da produção atinge um ritmo alucinante, principalmente na década de 1970.

A área colhida no estado se expandiu da casa dos 200 mil hectares, de 1960, para 4 milhões de hectares, em 1979, simplesmente multiplicando-se por 20 em 20 anos. A produção física, que também arranca das 200 mil toneladas em 1960, cresce espantosamente para atingir 5,6 milhões de toneladas, em 1977, e 6 milhões, em 1981, multiplicando-se por 30.

Os preços do produto, extremamente elevados, no mercado internacional nas safras de 1973 e 1974 provocaram o chamado "boom da soja". Sua participação na área total das lavouras do estado, que em 1960 era inferior a 10\%, ultrapas- 
sou os $40 \%$ na década de 80, e no VBPA sua participação passou de 5\% para 40\% no mesmo período (TRENNEPOHL, 1997).

O crescimento da produção de soja, inicialmente no Rio Grande do Sul e, em seguida, no Centro-Oeste brasileiro, se deu fundamentalmente através da incorporação de novas áreas de terra. O rendimento por hectare não apresentou incrementos significativos no período, caracterizando-se como uma cultura extensiva. Dessa forma, a sua expansão no estado encontrou limites na disponibilidade de terras (preço e qualidade), deslocando seu eixo de crescimento para outras regiões do país onde havia maior disponibilidade desse fator natural.

As novas condições de produção (custos e mercado) que se constituíram passaram a exigir escalas maiores para viabilizar a produção. Assim, muitos produtores gaúchos deslocaram-se para as regiões de fronteira agrícola do país, em busca de novas áreas de terra que lhes permitissem expandir sua escala de produção. Unidades de produção maiores e solos menos desgastados pelo cultivo foram as condições que favorecem as áreas novas de produção. Por outro lado, a proximidade do mercado (portos, indústrias, avicultura, suinocultura) e a existência de uma boa infraestrutura de produção (máquinas, equipamentos e sementes) e de comercialização (silos, armazéns, cooperativas, estradas) são elementos que contribuem para que a cultura mantenha um elevado grau de importância na economia gaúcha.

Em diversos municípios do planalto gaúcho, o milho apresentou expansão significativa e consolidou-se como cultura secundária da unidade de produção, possibilitando a rotação de culturas e a utilização compartilhada de grande parte do parque de máquinas agrícolas e equipamentos de produção e comercialização. Os incrementos de produtividade da cultura foram importantes para a redução de custos e a viabilização da demanda por rações advinda da pecuária intensiva em forte expansão.

\subsection{O Crescimento da Produção de Fumo na Região Central do Estado}

Também gerou impacto significativo no VBPA do Rio Grande do Sul e em sua distribuição municipal e regional o crescimento do valor da produção de fumo. Impulsionados pelos preços ofertados pelo mercado internacional, os fumicultores ampliaram suas áreas de produção, muitas vezes em detrimento de culturas como o feijão e o milho, e investiram em infraestrutura de estufas e sementeiras.

A produção de fumo, estreitamente integrada à indústria de beneficiamento e fabricação de cigarros, teve sua grande arrancada em 1914, quando a Souza Cruz, adotando o sistema de integração com as pequenas unidades produtivas rurais, passou a estimular o aumento da produção, produtividade e qualidade do produto. O núcleo pioneiro de Santa Cruz do Sul (RS) intensificou sua produção, e foram abertas novas áreas, inclusive, em Santa Catarina e no Paraná. 
O desenvolvimento da fumicultura no estado e no Brasil está diretamente ligado à estratégia e à dinâmica empreendida pelas companhias fumageiras (especialmente a Souza Cruz), que também possuem influências no mercado internacional. A área colhida de fumo no estado cresceu $234 \%$ ao longo do período e a produção física teve um crescimento de $455 \%$, indicando um aumento de $66 \%$ no rendimento médio. O valor bruto da produção teve um crescimento de $317 \%$, indicando certa estabilidade nos preços médios do produto provavelmente relacionado à melhoria da qualidade do fumo produzido e a sua melhor classificação para o mercado.

A cultura do fumo no Rio Grande do Sul é praticada principalmente nas zonas coloniais, onde predomina a pequena propriedade. Muito exigente em trabalho, a cultura tem por característica o emprego da força de trabalho familiar, existente em grande número nas regiões de produção.

A principal característica da produção de fumo é a integração e completa submissão das unidades produtivas agrícolas às orientações das companhias industriais. As companhias financiam a construção de estufas ou galpões, a aquisição de máquinas e equipamentos, fornecem os insumos agrícolas necessários, prestam assistência técnica intensiva, etc. em troca da garantia de entrega do produto.

Trata-se de uma cultura muito exigente, produzida através de um pacote tecnológico caro e complexo. As exigências em termos de conhecimentos técnicos sobre a produção, o volume de capital necessário e a oligopolização do mercado praticamente impossibilita a produção não integrada, de forma autônoma pelas unidades agrícolas.

Apesar de toda essa dependência e submissão do produtor rural aos ditames das indústrias, a atividade fumageira tem se mostrado remuneradora, se comparada a outras atividades agrícolas. Evidentemente não se está falando em termos de capitalização dos produtores, até porque isso poderia torná-los independentes, mas em termos de absorver um grande contingente de força de trabalho e de remunerá-lo dentro dos padrões brasileiros.

A dinâmica de desenvolvimento da atividade é determinada diretamente pelas companhias industriais, que produzem e repassam aos produtores rurais os avanços tecnológicos que se fazem necessários. É uma atividade literalmente organizada pelas grandes companhias que, de acordo com sua inserção no mercado nacional e internacional, determinam a quantidade, a qualidade, os preços e os locais de produção.

\subsection{A Expansão da Lavoura de Arroz na Região da Campanha}

Outro movimento que gerou grande impacto no VBPA do Rio Grande do Sul foi a expansão da lavoura de arroz em vastas áreas de terras ocupadas pela pecuária extensiva na região da Campanha. 
O Rio Grande do Sul foi o estado que liderou a arrancada de produção nacional de arroz, impulsionada pela introdução da irrigação mecânica em 1903, no município de Pelotas. Os fartos mananciais de água e as extensas várzeas existentes ao longo de toda a depressão central foram importantes para que a nova tecnologia tivesse rápida difusão e a área cultivada com arroz fosse ampliada. A análise da rizicultura gaúcha no período leva em conta que se trata de uma atividade que se desenvolve sobre bases empresariais desde o início do século. Foram feitos pesados investimentos em capital fixo e em tecnologia de ponta na cultura. Portanto, trata-se de observar o desenvolvimento de uma atividade que formou e consolidou sua estrutura produtiva antes do período analisado.

Os dados analisados, referentes ao período 1970-2006, mostram claramente que a cultura do arroz seguiu em franco crescimento no estado. A área colhida dobrou e na produção física o crescimento foi ainda mais acentuado, praticamente quadruplicando no período, em função dos ganhos de produtividade por unidade de área que elevaram o rendimento médio de $3.000 \mathrm{~kg} / \mathrm{ha}$ para quase $6.000 \mathrm{~kg} /$ ha. Sua expansão ocorreu, principalmente, na região da Campanha, em terras de várzeas anteriormente utilizadas pela pecuária extensiva.

O valor bruto da produção de arroz, que em 1970 foi de $\mathrm{R} \$ 1,37$ bilhão (valores corrigidos para 2006), cresceu 63\% e atingiu o montante de $R \$ 2,23$ bilhões em 2006. Em termos absolutos, o valor da produção aumentou em $R \$ 863,6$ milhões, contribuindo com $25 \%$ do crescimento do VBPA total do estado. O crescimento do volume de produção física de arroz foi mais expressivo e não se refletiu integralmente no valor da produção devido à diminuição do preço médio registrado entre as duas datas consideradas, que foi de $58,2 \%$.

Dessa forma, o estado aumentou significativamente a sua importância no cenário nacional da produção de arroz. A rizicultura gaúcha beneficiou-se enormemente com os avanços da indústria de máquinas e equipamentos agrícolas (que foram aperfeiçoados, melhorando o seu desempenho e generalizando a sua utilização), da indústria de fertilizantes e corretivos químicos, da indústria de defensivos agrícolas (permitindo o cultivo mais intensivo das terras, sem reduzir o rendimento) e da própria indústria de beneficiamento do arroz. $\mathrm{O}$ acesso à energia elétrica, embora ainda não garantido a todos, também permitiu avanços importantes na irrigação, reduzindo significativamente os custos.

$\mathrm{O}$ avanço da pesquisa, criando variedades mais produtivas e desenvolvendo novos métodos de cultivo, é outro aspecto importante a ser destacado. Também ocorreram avanços na área da comercialização e industrialização do arroz com o desenvolvimento de novos equipamentos para secagem, armazenamento e beneficiamento do produto, reduzindo as perdas e aumentando a qualidade e a variedade de produtos oferecidos ao mercado (arroz parboilizado, arroz malekizado, óleo de arroz, flocos, etc.). 
Porém, todo esse desenvolvimento da rizicultura não conseguiu superar um problema que se recoloca a todo momento: o mercado. Embora seja uma atividade moderna, com tecnologia avançada e alta intensidade de capital, o seu produto destina-se ao consumo da grande massa popular. $\mathrm{O}$ arroz é um alimento básico da população e a maior quantidade do produto continua sendo consumida pela população de baixa renda. Por isso, o seu mercado encontra-se tão retraído quanto está concentrada a renda nesse país. O efêmero momento histórico de melhoria da renda da população ocorrido durante o Plano Cruzado, em 1986, serve de exemplo e demonstra claramente que os limites do mercado não são determinados pela fome ou pela necessidade nutricional da população, mas pela renda disponível para adquirir os alimentos.

\subsection{Impactos da Produção de Bovinos de Corte e da Ovinocultura}

Os dados analisados não permitem identificar com maior clareza os impactos do desempenho dessas atividades especificamente, pois nos censos agropecuários estão agregados em grandes animais (bovinos de carne e leite, equinos, bubalinos, etc.) e em animais de médio porte (ovinos, suínos, caprinos, etc.). Entretanto, a observação do comportamento do VBPA desses dois grupos nos diversos municípios e da evolução do VBPA do leite e da lã no estado permite considerar como hipótese bastante provável a perda significativa ocasionada pela redução de valor da pecuária extensiva, especialmente a bovinocultura de corte e a ovinocultura.

Os municípios de Alegrete, Santana do Livramento, Bagé, Dom Pedrito, Uruguaiana, São Gabriel e Quaraí são os que apresentaram as maiores perdas no VBPA dos grupos de grandes animais e de animais de médio porte e, consequentemente, perdas no valor global do município. Parece evidente que o desempenho geral tenha sido fortemente influenciado pela bovinocultura de corte e pela ovinocultura. Em diversos casos, tais perdas foram compensadas pelo desempenho positivo da produção de arroz, que teve forte expansão registrada pelo censo de 1996 e também pelo avanço das lavouras de soja.

O comportamento das lavouras de soja e arroz, principalmente avançando sobre as áreas de campo destinadas à pecuária extensiva, explica em parte a tendência de queda do valor da produção de bovinos de corte e de ovinos. Houve uma redução significativa das áreas de pasto nativo, mas, em contrapartida, uma expansão da área de pastagens cultivadas em rotação com a produção de arroz e de soja.

O principal problema da produção é a alimentação dos animais durante o período de inverno. As pastagens naturais, que são fartas e de boa qualidade durante o verão, perdem totalmente suas qualidades no inverno. O cultivo de pastagens artificiais e outras formas de melhorar a alimentação durante o inverno teriam resultados significativos no desempenho da pecuária de corte no estado. 
Além disso, criariam oportunidade de viabilização de outros procedimentos complementares, que poderiam resultar em ganhos de produtividade.

O mercado da carne bovina tem se mostrado bastante instável, colocando em risco os investimentos na atividade, normalmente a longo prazo. O achatamento salarial, a concentração de renda e a concorrência de carnes mais baratas (frangos) reduziram significativamente o espaço da carne bovina no mercado interno. No mercado externo, o problema tem sido a falta de competitividade do produto brasileiro e gaúcho frente aos melhores índices de produtividade da $\mathrm{Ar}$ gentina, Austrália e Nova Zelândia e frente aos pesados subsídios da União Europeia e dos Estados Unidos.

\subsection{Os Fenômenos da Lavoura Permanente e da Silvicultura}

Apesar de não ter gerado um grande impacto no VBPA total do Rio Grande do Sul, o crescimento espetacular da produção de maçã pode ser considerado um fenômeno por suas características. Uma atividade inexpressiva em 1970 passou a ser produzida em municípios que descobriram sua aptidão para a cultura muito lentamente e que superaram em valor de produção outras atividades tidas como mais promissoras. Além do mais, sua produção ocorre de forma bastante concentrada em menos de uma dezena de municípios, onde contribui decisivamente para o desempenho do VBPA municipal.

O ano de 1977 pode ser considerado como marco na transformação da atividade. Até então, os poucos pomares existentes eram constituídos por variedades sem maior qualidade, implantados empiricamente, e o produto era colocado a granel no mercado regional sem contar com nenhuma infraestrutura de comercialização. O mercado nacional era abastecido basicamente pelas importações, principalmente da Argentina. Com a implementação do Projeto de Fruticultura de Clima Temperado (Profit), e oferecendo incentivos fiscais, crédito rural e assistência técnica, foram instalados pomares com novas variedades e investimentos em infraestrutura de processamento e comercialização. O principal argumento dos técnicos que elaboraram o Profit era substituir as importações da fruta pela produção nacional (NEUMANN, 1997).

Muitas variedades foram introduzidas, sendo que algumas não se adaptaram devido aos baixos índices de produtividade, enquanto outras, apesar de produtivas, não tiveram aceitação no mercado. Ao longo do tempo, foram despontando as variedades Gala e Fugi, por suas características de produtividade, sabor e apresentação. O município de Vacaria se destacou no estado e no país, tanto na área plantada quanto na capacidade de armazenamento frigorífico e equipamentos de classificação e embalagem. Foram determinantes, para o desenvolvimento da atividade, o clima e o solo apropriados, permitindo a mecanização e a implantação 
de extensas áreas de pomares, em resposta aos incentivos fiscais oferecidos pelas políticas públicas.

Outros municípios próximos, como Bom Jesus, São Francisco de Paula e Cambará do Sul, também com ótimas condições de clima e solo, apresentaram crescimento na atividade, porém em ritmo inferior, considerando as dificuldades de acesso ao mercado oriundas da falta de infraestrutura e das péssimas condições das estradas federais.

A produção nacional, impulsionada principalmente pela produção do Rio Grande do Sul e Santa Catarina, cresceu significativamente e passou a abastecer o mercado nacional, cujo consumo também apresentou crescimento expressivo. O desenvolvimento da atividade, com ganhos significativos de produtividade e redução de custos, proporcionou uma queda nos preços da fruta ao consumidor e uma popularização do consumo.

Situações semelhantes podem ser identificadas com outras lavouras permanentes, como a de erva-mate em llópolis e as frutíferas de clima temperado (além das de maçã, ameixa, uva e outras) em Bento Gonçalves, Caxias do Sul e Flores da Cunha.

Outro fenômeno de grande impacto foi a expansão da silvicultura nos municípios de Triunfo, Piratini, São Francisco de Paula, Osório e Montenegro, que impulsionou o VBPA desses municípios para patamares de destaque estadual no período.

\subsection{A Queda no VBPA na Região Metropolitana da Capital Gaúcha}

Um movimento que gerou impacto negativo no VBPA do Rio Grande do Sul e em sua distribuição municipal e regional foi o processo de urbanização da população gaúcha e, especialmente, da rápida concentração populacional na região metropolitana de Porto Alegre. Áreas de produção agropecuária foram urbanizadas e redirecionadas em suas finalidades, com impactos na redução do valor da produção agropecuária desses municípios.

\section{Considerações Finais}

O objetivo deste artigo é socializar as principais constatações feitas na análise sobre a evolução do VBPA dos municípios gaúchos no período de 1970 a 2006.

A primeira grande constatação foi quanto à utilização do novo ferramental metodológico de conversão dos dados. Sem a ajuda desse programa de conversão seria muito difícil, se não impossível, fazer uma análise intertemporal com tamanha confiabilidade. Sem dúvida, as possibilidades que esse ferramental apresenta são muitas para os pesquisadores do desenvolvimento. 
Diante dos resultados, ficaram evidentes as alterações espaciais das principais atividades da agropecuária do Rio Grande do Sul. As dinâmicas da conjuntura econômica nacional, do processo de mecanização e tecnificação do campo e do processo de urbanização contribuíram para esse fenômeno e para a consolidação da identidade regional gaúcha. Além disso, a implantação de empresas agroindustriais de grande porte no estado contribuiu para a difusão de algumas atividades, em especial, a de abate de aves e a de transformação do leite.

O estado está caminhando para a consolidação de três grandes regiões: do Sul, com o binômio arroz/bovinocultura, do Noroeste, com a produção de grãos, em especial soja e milho, e do Centro-Leste, como a região mais diversificada, com forte presença da fruticultura e da pecuária intensiva, em especial, a suinocultura, a avicultura e a produção leiteira.

\section{Referências}

ALVES, L. R. Distribuição das atividades econômicas e desenvolvimento regional em mesorregiôes selecionadas do sul do Brasil: 1970 a 2000. 2008. 183 f. Dissertação (Mestrado em Desenvolvimento Regional) - Universidade de Santa Cruz do Sul, Santa Cruz do Sul, 2008.

BASSO, D.; SILVA NETO, B. (Org.). Sistemas agrários do Rio Grande do Sul. Jjuí: Unijuí, 2005. $307 \mathrm{p}$.

IBGE. Censo agropecuário 2006. Disponível em: < www.sidra.ibge.gov.br > . Acesso em: fev. 2011. IBGE, 1998.

Censo agropecuário 1995-1996: número 22, Rio Grande do Sul. Rio de Janeiro:

. Censo agropecuário: Rio Grande do Sul. Rio de Janeiro: IBGE, 1974. (VIII Recenseamento Geral - 1970, Série Nacional, v. III, Tomo XXI).

FUNDAÇÃO DE ECONOMIA E ESTATÍSTICA. Duas décadas da produção e do produto da agropecuária do Rio Grande do Sul. Porto Alegre: FEE, 1986. 3 tomos.

NEUMANN, T. S. A evolução da produção de maçã no Sul do Brasil: perspectivas de crescimento e competitividade. 1997. 91 p. Monografia (Graduação em Ciências Econômicas) - Universidade de Santa Cruz do Sul, Santa Cruz do Sul, 1997.

PAIVA, C. A. N. Como identificar e mobilizar o potencial de desenvolvimento endógeno de uma região? Porto Alegre: FEE, 2004. 140 p. (Documentos FEE, n. 59).

(Coord.). RS em mapas e dados: bases georreferenciadas para a comparação do desempenho socioeconômico dos municípios gaúchos entre 1966 e 2006. Porto Alegre: FEE, 2007. Disponível em: <http://www.fee.tche.br/rs-em-mapas-e-dados/sistema.html> Acesso em: 16 fev. 2011.

TRENNEPOHL, D. Avaliação da contribuição potencial das principais atividades agropecuárias para o desenvolvimento econômico da Região Noroeste do Rio Grande do Sul. 2010. 216 f. Tese 
(Doutorado em Desenvolvimento Regional) - Universidade de Santa Cruz do Sul, Santa Cruz do Sul, 2010.

. O processo de desenvolvimento recente da agropecuária gaúcha. Ijuí: Editora da Unijuí, 1997. 168p. Dissertação de Mestrado.

TRENNEPOHL, D.; ALVES, L. R.; FLORES, A. J. Análise das características regionais e setoriais da evolução do valor bruto da produção agropecuária municipal no Rio Grande do Sul entre 1970 e 1996. In: PAIVA, C. A. N. (Coord.). RS em Mapas e Dados. Porto Alegre: FEE, 2007.

Recebido em: 09/09/2011.

Aceito em: 06/12/2012. 